\title{
Enhancers and hindrances to doctor-nurse interdisciplinary collaborative practice in Nigeria
}

\author{
Ijeoma L. Okoronkwo ${ }^{1 *}$, John E. Anieche ${ }^{1,2}$, Anthonia U. Chinweuba ${ }^{1}$, Afam C. Ndu ${ }^{1,3}$ \\ ${ }^{1}$ Department of Nursing Sciences, University of Nigeria, Enugu, Nigeria \\ ${ }^{2}$ Department of Nursing Sciences, Nnamdi Azikiwe University, Awka, Nigeria \\ ${ }^{3}$ Post Basic School of Psychiatric Nursing, Federal Neuropsychiatric Hospital, Enugu, Nigeria \\ Email: ĳeoma.okoronkwo@unn.edu.ng, amakauwy@yahoo.com, aniechejb@yahoo.com, afamci@yahoo.com
}

Received 14 November 2012; revised 20 March 2013; accepted 16 April 2013

Copyright (C) 2013 Ijeoma L. Okoronkwo et al. This is an open access article distributed under the Creative Commons Attribution License, which permits unrestricted use, distribution, and reproduction in any medium, provided the original work is properly cited.

\section{ABSTRACT}

The purpose of this study was to identify factors that enhance and hinder interdisciplinary collaborative practice (ICP) among doctors and nurses at the Nnamdi Azikiwe teaching hospital, Nnewi, southeast Nigeria. The study was a cross-sectional descriptive survey and the quantitative method of data collection was employed. The population was all doctors irrespective of area of specialty and all nurses employed and working in the hospital as at the time of study. Proportionate stratified and convenience sampling methods were used to select study participants according to their categories. Using validated structured questionnaire, data were collected from 110 doctors and 95 nurses in the teaching hospital on their perception on ICP and factors that enhance/hinder ICP. Data were analyzed using both descriptive and inferential statistics. Specifically, frequencies, percentages, standard deviation and graphic presentation were used for descriptive analysis of scores while the unpaired $t$ test of mean score using Graph Pad Prism, Version 5.30 was used to determine the influence of profession, gender, and years of experience on perception of ICP at 0.05 level of significance. The study found that both doctors and nurses have positive perception on ICP. Their years of experience have significant influence on their perception. Clear individual roles and good working relationships enhance ICP while giving priority to professional status rather than expertise was seen as a prominent hindrance to ICP. The study recommends collaborative continuing education for doctors and nurses to enhance ICP in patient care. In addition, the inclusion of interdisciplinary collaborative practice programmme into the curriculum of medical and nursing students (where it does not exist)

\footnotetext{
"Corresponding author.
}

would go a long way to strengthen ICP and decrease hindrances when they graduate.

Keywords: Enhancers; Hindrances; Doctor-Nurse; Interdisciplinary Collaborative Practice; Nnamdi Azikiwe University Teaching Hospital; Nnewi; Nigeria

\section{INTRODUCTION}

Clients who come to healthcare institutions have multidimensional problems. A client's problem in one dimension affects the other. No single discipline can cope with the multiplicity of needs of patients which varies-medical, nursing, rehabilitative, social, among others [1]. A combination of skills and knowledge of several health professionals are needed to maximize efficiency of the health care system $[2,3]$. In addition, consumers of healthcare now demand quality, comprehensive care due to increasing cost of healthcare services. Such comprehensive care can only be possible when healthcare providers collaborate to integrate the care given to clients.

Interdisciplinary Collaborative Practice (ICP) is the process by which different professional groups work together to positively impact healthcare. It involves a negotiated agreement between professionals which values the expertise and contributions that various healthcare professionals bring to patient care. It also involves issues that arise due to different professionals working together, such as problematic power dynamics and poor communication conflicts due to varied approaches to patient care [4-7].

Available literatures show variations on healthcare professionals' view on collaborative practice. In a crosssectional study of how Israeli complimentary practitioners and physicians communicate, it was observed that $69 \%$ of the physicians and $77 \%$ of Complementary and Alternative Medicine (CAM) practitioners shared a posi- 
tive view about collaboration [8]. However, the CAM practitioners were more interested than the physicians in collaborative scientific research $-27 \%$ and $2 \%$, respectively. In the same study, $424(82 \%)$ of 517 primary care physicians had formal relationships with other physicians but not with Chiropractors (CAM Practitioners). Findings of the study suggest physicians' preference for intra-disciplinary rather than inter-disciplinary collaboration. The researchers concluded that such findings will not be seen as truly supportive of collaborative practice because collaborative practice requires distribution of power-sharing with more competent personnel leading the team at a particular time depending on required expertise and patient's disease condition.

In a similar study on doctor-nurse collaboration using 277 doctors and 372 nurses in USA and Mexico [9], the USA based doctors and nurses expressed more positive perception towards collaboration than their counterparts in Mexico. In the same study, the female subjects expressed more positive attitude than their male counterparts. The researchers suggested that collaborative education be introduced for medical and nursing students to promote higher positive attitude towards complementary role functions. However, it has been suggested that length of experience in clinical practice enhances collaborative practice [10]; though the study was not specific on nurse/ doctor collaboration. The question is will years of experience of these doctors and nurses influence their ICP?

Doctors and nurses are the healthcare professionals that work closely together with clients/patients in healthcare institutions and therefore need to collaborate with one another for effective and efficient client care that will yield expected outcome at the shortest possible time, and at reduced cost. The success of these groups of professionals lies in their ability to work and interact together as a team. However, according to the work of [11, 12] a historical tension exists between doctors and nurses which has an adverse effect on client care. In another study on the perception of ICP among a team of healthcare professionals in Sweden [6] the respondents were of the opinion that ICP has a negative impact on patient care and thus problematic. Studies in USA and Canada have documented the impact of communication problems on work processes and patient safety in surgery [13-15].

In Nigeria, the researchers observed that patients and/ or their caregivers occasionally are the nurses' source of information on doctors' plan of patient care. Similarly, nurses sometimes fail to communicate client problems identified during assessment to the doctors. One, therefore, wonders if the doctors and nurses perceive ICP as an important tool in their patient care. What factors in the doctors and nurses enhance and hinder their use of ICP in their clinical practice? Specifically the research questions for this study are:
1) How do doctors and nurses in this teaching hospital, perceive ICP?

2) What is the association between gender of doctors and nurses and their perception of ICP?

3) What is the association between years of experience of doctors and nurses and their perception of ICP?

4) What are the factors that may enhance ICP as perceived by doctors and nurses?

5) What are the factors that may hinder ICP as perceived by doctors and nurses?

\section{METHOD}

A cross-sectional descriptive survey was carried out at the Nnamdi Azikiwe University teaching hospital, Nnewi south east of Nigeria.

\subsection{Population of Study}

The population of study was made up of all medical doctors, irrespective of area of specialty, and all nurses employed by the hospital. According to records provided by the personnel department of the hospital, there were 300 medical doctors and 278 nurses making a total population of 578 .

\subsection{Sample}

A sample size of 236 subjects determined using Yaro Yamane's formula for estimating sample size in a finite population [16] was used. This is about $40.8 \%$ of the population. A proportionate stratified sampling technique (proportionate representation of the population) was applied and 122 doctors and 114 nurses were drawn into the study. Furthermore, the subjects were classified by gender and cadre to capture all categories of doctors and nurses; thus 56 male, 32 female doctors with $<6$ years of working experience; 23 male, 11 female doctors $>6$ years; 4 male, 37 female nurses with $<6$ years and 8 male, 65 female nurses $>6$ years were used. Convenience sampling was used to collect data from the doctors and nurses based on the various categories until the desired number in each segment was reached.

\subsection{Data Collection}

A 23-item developed ICP questionnaire was used for data collection. Ten of the items were designed to collect data on subjects' perception on ICP; seven items elicited information on enhancers while six items allowed subjects to report hindrances to their use of inter-disciplinary collaboration. These items were presented in a 4-point rating scale of strongly agree (SA), agree (A), disagree (D) and strongly disagree (SD). The responses were weighted accordingly: $\mathrm{SA}=4, \mathrm{~A}=3, \mathrm{D}=2$, and $\mathrm{SD}=1$ for items with positive statements, while for negative statement 
items, $\mathrm{SD}=4, \mathrm{D}=3, \mathrm{~A}=2$ and $\mathrm{SA}=1$. Also, personal data on profession, gender and years of working experience were sought. To establish its validity, a professor in the Department of Measurement and Evaluation in the University of Nigeria, Nsukka, was requested to comment on the adequacy of the items for answering the research questions. After due modifications, the instrument was pilot-tested by administering twenty copies of it to ten doctors and ten nurses in the University of Nigeria Teaching Hospital (UNTH), Ituku-Ozalla. Responses were subjected to split-half test using Pearson's Product Moment Correlation Coefficient $(r)$. With $r=0.89$, the instrument was considered reliable. Copies of the questionnaire were subsequently administered by researchers' personal contacts with the doctors and nurses in the consulting rooms and on the wards after explanation of research purpose. Subjects were approached and requested to fill in their responses as carefully and objectively as possible at their convenient times. Retrieval was also by personal contact. Out of the 236 copies distributed, 205 were retrieved giving a return rate of $87 \%$. Administration and retrieval of the instrument lasted for one month.

\subsection{Ethical Consideration}

Ethical clearance was obtained from the hospital's ethical committee and informed consent was obtained from all the respondents who were given the option of not participating if they so wished.

\subsection{Data Analysis}

Data generated were analyzed using both descriptive and inferential statistics. Specifically, frequencies, percentages, means and standard deviation were used for descriptive analysis of scores while unpaired $t$ test of mean score with Graph Pad Prism, Version 5.30 was used to determine the association of profession, gender, and years of experience and their perception of ICP at 0.05 level of significance.

\section{RESULTS}

Out of the 205 respondents, $110(54 \%)$ were medical doctors while $95(46 \%)$ were nurses (Table 1). There were $70(64 \%)$ male doctors and $40(36 \%)$ female doc- tors. The female nurses were $88(93 \%)$ while the male nurses were only 7 (7\%). Out of the 110 doctors, 85 $(77 \%)$ have their practice experience below 6 years while $25(23 \%)$ have practice experience above 6 years. Out of the 95 nurses $60(63 \%)$ have practice experience above 6 years while $32(37 \%)$ have practice experience below 6 years.

Both doctors and nurses perceived ICP as a team approach towards needs assessment (mean: doctors $=40.7$, nurses $=34.6$ ); both identifying patient's needs together (mean: doctors $=40.0$, nurses $=34.9$ ); not considering status during entire care process (mean: doctors $=38.5$, nurses $=35.0$ ); either party influencing the other's decisions for goal achievement (mean: doctors $=30.5$, nurses $=27.7)$ and that skills of both are needed to plan appropriate care (mean: doctors $=29.8$, nurses $=28.9)($ Table 2). Importantly, both rejected the statement that collaboration does not necessarily mean doctors and nurses agreeing on patient's needs before planning care (mean: doctors $=22.0$, nurses $=13.2$ ); both agreeing on patient priority care selection (mean: doctors $=25.7$, nurses $=$ 13.6) and that disagreement on actions taken by either party does not require joint discussion of both parties (mean: doctors $=25.0$, nurses $=16.8$ ). However, while the nurses agreed that collaboration involves both jointly agreeing on who leads the team considering patient care needs $($ mean $=29.7)$ and clear communication of actions by all collaborators $($ mean $=24.3)$, the doctors disagreed on these (mean $=27.2$ and 25.4), respectively. Unpaired t test of the mean scores at $\alpha=0.05$ showed no significant difference $(\mathrm{t}=1.328 ; \mathrm{df}=18 ; \mathrm{p}=0.2009)$.

Association of gender of doctors and nurses on perception of ICP was related (Table 3). With confidence interval of -28.21 to 8.615 , unpaired $t$ test of the mean scores at 0.05 level of significance showed no significant difference in their perception ( $\mathrm{p}$ value $=0.2782, \mathrm{df}=18$, $t=1.118$ ). Except for both jointly agreeing on who leads the team considering patient care needs $($ mean $=10.9)$ and clear communication of actions by all collaborators $($ mean $=17.3)$ for the males, mean score for all variables were above the average score of 19. All females scored means above the 32.25 average score for females.

As shown in Table 4, years of experience of doctors and nurses were significantly associated with their per-

Table 1. Socio-demographic data of the respondents.

\begin{tabular}{ccccccccc}
\hline & \multicolumn{8}{c}{ DOCTORS NURSES } \\
\cline { 2 - 9 } & \multicolumn{9}{c}{ MALE FEMALE } & \multicolumn{5}{c}{ MALE FEMALE } \\
\cline { 2 - 9 } & $\mathbf{N}$ & $\mathbf{\%}$ & $\mathbf{N}$ & $\mathbf{\%}$ & $\mathbf{N}$ & $\mathbf{\%}$ & $\mathbf{N}$ & $\mathbf{\%}$ \\
\hline YEARS OF EXPERIENCE & 70 & 34.15 & 40 & 19.51 & 7 & 3.41 & 88 & 42.93 \\
\hline$<6$ years & & & & & & & & \\
\hline$>6$ years & 54 & 26.34 & 31 & 15.12 & 2 & 0.98 & 30 & 14.63 \\
\hline & 16 & 7.8 & 9 & 4.39 & 5 & 2.44 & 58 & 28.29 \\
\hline
\end{tabular}


Table 2. Unpaired t test of mean scores on ICP by profession.

\begin{tabular}{|c|c|c|c|}
\hline & & $\begin{array}{c}\text { DOCTORS } \\
(\mathrm{n}=\mathbf{1 1 0}, \mathrm{x}=\mathbf{2 7 . 5}) \\
\end{array}$ & $\begin{array}{c}\text { NURSES } \\
(\mathrm{n}=\mathbf{9 5}, \mathrm{x}=\mathbf{2 3 . 7 5 )} \\
\end{array}$ \\
\hline & $\mathrm{SN}$ & $\mathbf{x}$ & $\mathbf{x}$ \\
\hline 1 & Team approach by doctors and nurses in needs assessment & 40.7 & 34.6 \\
\hline 2 & Both together identify patient's needs & 40.0 & 34.9 \\
\hline 3 & Doctors and nurses not necessarily agreeing on patient's needs before planning care & 22.0 & 13.2 \\
\hline 4 & Skills of both are needed to plan appropriate care & 29.8 & 28.9 \\
\hline 5 & Both not necessarily agreeing on patient priority care selection & 25.7 & 13.6 \\
\hline 6 & Both jointly agree on who leads the team considering care needs & 27.2 & 29.7 \\
\hline 7 & Clear communication of actions by all collaborators & 25.4 & 24.3 \\
\hline 8 & Status not considered during entire care process & 38.5 & 35.0 \\
\hline 9 & Either party can influence the other's decisions for goal achievement & 30.5 & 27.7 \\
\hline 10 & Disagreement on actions taken by either party does not require joint discussion of both parties & 25.0 & 16.8 \\
\hline & $\begin{array}{c}\text { Unpaired t test } \\
\mathrm{p} \text { value } \\
\mathrm{t} \\
\mathbf{d f} \\
\mathbf{9 5 \%} \mathbf{C I} \\
\text { Are means sig. diff? }(\mathrm{p}<0.05)\end{array}$ & $\begin{array}{r}0 \\
1 \\
-2.68\end{array}$ & $\begin{array}{l}9 \\
8 \\
11.91\end{array}$ \\
\hline
\end{tabular}

Table 3. Unpaired t test of mean scores on ICP by gender.

\begin{tabular}{|c|c|c|c|}
\hline & & $\begin{array}{c}\text { MALE } \\
(n=76, x=19)\end{array}$ & $\begin{array}{c}\text { FEMALE } \\
(\mathrm{n}=\mathbf{1 2 9}, \mathrm{x}=\mathbf{3 2 . 2 5 )}\end{array}$ \\
\hline & SN & $\mathbf{x}$ & $\mathbf{x}$ \\
\hline 1 & Team approach by doctors and nurses in needs assessment & 27.6 & 47.7 \\
\hline 2 & Both together identify patient's needs & 27.5 & 47.4 \\
\hline 3 & Doctors and nurses not necessarily agreeing on patient's needs before planning care & 24.7 & 47.1 \\
\hline 4 & Skills of both are needed in to plan appropriate care & 20.8 & 37.9 \\
\hline 5 & Both not necessarily agreeing on patient priority care selection & 24.4 & 44.1 \\
\hline 6 & Both jointly agree on who leads the team considering patient care needs & 10.9 & 38.0 \\
\hline 7 & Clear communication of actions by all collaborators & 17.3 & 32.4 \\
\hline 8 & Status not considered during entire care process & 27.2 & 46.3 \\
\hline 9 & Either party can influence the other's decisions for goal achievement & 20.6 & 37.6 \\
\hline 10 & Disagreement on actions taken by either party does not require joint discussion of both parties & 22.8 & 41.4 \\
\hline & $\begin{array}{c}\text { Unpaired } \mathbf{t} \text { test } \\
\mathrm{p} \text { value } \\
\mathrm{t} \\
\mathbf{d f} \\
\mathbf{9 5 \%} \mathbf{C I} \\
\text { Are means sig. diff? }(\mathrm{p}<0.05)\end{array}$ & $\begin{array}{r}< \\
-24.5\end{array}$ & $\begin{array}{l}01 \\
30 \\
-14.63\end{array}$ \\
\hline
\end{tabular}

ception of ICP. At alpha level of 0.05 and df 18, twotailed $p$ value of unpaired t test of the mean scores was 0.0002 and $\mathrm{t}=4.641$. While all variables maintained mean scores above their average except for clear communication of actions by all collaborators (mean $<6$ years $=21.3,>6$ years $=28.4$ - with wide gap between them), averages for those $>6$ years were higher than for those $<6$ years. Thus, confidence interval was from 5.396 to 14.32 . Those who have put in $\geq 6$ years had more positive perception of ICP than those with $<6$ years.

Clearly written and oral communication, good working relationships, long clinical experience and clarifying individual roles were identified most frequently by respondents as enhancers of ICP (Table 5). With mean of 72.9 and standard deviation of 58.43, 119 (58.1\%) of respondents would want clearly written or oral communication to enhance their collaboration in practice. This was followed by the existence of good working relationships $($ mean $=72.0 ;$ standard deviation $=55.42)$. How- 
Table 4. Unpaired t test of mean scores on ICP by years of practice.

\begin{tabular}{|c|c|c|c|}
\hline & & $\begin{array}{c}<6 \text { years } \\
(\mathrm{n}=117, \mathrm{x}=29.25)\end{array}$ & $\begin{array}{c}\geq 6 \text { years } \\
(n=88, x=22)\end{array}$ \\
\hline $\mathrm{SN}$ & & $\mathbf{x}$ & $\mathbf{x}$ \\
\hline 1 & Team approach by doctors and nurses in needs assessment & 31.1 & 44.2 \\
\hline 2 & Both together identify patient's needs & 30.9 & 44.0 \\
\hline 3 & Doctors and nurses not necessarily agreeing on patient's needs before planning care & 30.1 & 40.2 \\
\hline 4 & Skills of both are needed in to plan appropriate care & 21.9 & 33.8 \\
\hline 5 & Both not necessarily agreeing on patient priority care selection & 29.8 & 39.1 \\
\hline 6 & Both jointly agree on who leads the team considering patient care needs & 25.6 & 31.3 \\
\hline 7 & Clear communication of actions by all collaborators & 21.3 & 28.4 \\
\hline 8 & Status not considered during entire care process & 30.9 & 42.6 \\
\hline 9 & Either party can influence the other's decisions for goal achievement & 25.4 & 32.8 \\
\hline 10 & Disagreement on actions taken by either party does not require joint discussion of both parties & 27.5 & 36.7 \\
\hline & $\begin{array}{c}\text { Unpaired t test } \\
\text { p value } \\
\mathbf{t} \\
\mathbf{d f} \\
\mathbf{9 5 \%} \mathbf{C I} \\
\text { Are means sig. diff? }(\mathrm{p}<0.05)\end{array}$ & $\begin{array}{r}0.0 \\
4.6 \\
1 \\
5.396 \mathrm{t} \\
\mathrm{Y}\end{array}$ & 4.32 \\
\hline
\end{tabular}

Table 5. Perceived interdisciplinary collaborative enhancers.

\begin{tabular}{|c|c|c|c|c|c|c|}
\hline Enhancers & Strongly Agree & Agree & Disagree & Strongly Disagree & Mean & Std Dev \\
\hline Clarifying individual roles & $\begin{array}{c}100 \\
(48.8 \%)\end{array}$ & $\begin{array}{c}92 \\
(44.9 \%)\end{array}$ & $\begin{array}{c}8 \\
(3.9 \%)\end{array}$ & $\begin{array}{c}5 \\
(2.44 \%)\end{array}$ & 69.7 & 51.79 \\
\hline Clearly written and oral communication & $\begin{array}{c}119 \\
(58.1 \%)\end{array}$ & $\begin{array}{c}81 \\
(39.5 \%)\end{array}$ & $\begin{array}{c}5 \\
(2.4 \%)\end{array}$ & $\begin{array}{c}0 \\
(0 \%)\end{array}$ & 72.9 & 58.43 \\
\hline Both doctors and nurses agreeing on choice of care & $\begin{array}{c}59 \\
(28.8 \%)\end{array}$ & $\begin{array}{c}86 \\
(42.0 \%)\end{array}$ & $\begin{array}{c}41 \\
(20 \%)\end{array}$ & $\begin{array}{c}19 \\
(9.8 \%)\end{array}$ & 59.7 & 28.36 \\
\hline Good working relationships & $\begin{array}{c}117 \\
(57.1 \%)\end{array}$ & $\begin{array}{c}77 \\
(37.6 \%)\end{array}$ & $\begin{array}{c}10 \\
(4.9 \%)\end{array}$ & $\begin{array}{c}1 \\
(0.5 \%)\end{array}$ & 72.0 & 52.42 \\
\hline Long clinical experience & $\begin{array}{c}106 \\
(51.7 \%)\end{array}$ & $\begin{array}{c}82 \\
(40 \%)\end{array}$ & $\begin{array}{c}16 \\
(7.8 \%)\end{array}$ & $\begin{array}{c}1 \\
(0.5 \%)\end{array}$ & 70.3 & 50.70 \\
\hline Individual doctors' and nurses' inputs needed to plan care & $\begin{array}{c}13 \\
(6.34 \%)\end{array}$ & $\begin{array}{c}66 \\
(32.2 \%)\end{array}$ & $\begin{array}{c}80 \\
(39 \%)\end{array}$ & $\begin{array}{c}46 \\
(22.4 \%)\end{array}$ & 45.6 & 29.07 \\
\hline Both doctors and nurses influencing other's decision & $\begin{array}{c}67 \\
(32.7 \%)\end{array}$ & $\begin{array}{c}108 \\
(52.7 \%)\end{array}$ & $\begin{array}{c}20 \\
(9.8 \%)\end{array}$ & $\begin{array}{c}10 \\
(4.9 \%)\end{array}$ & 64.2 & 45.26 \\
\hline
\end{tabular}

ever, least recognition was given to personal inputs of members for planning of care (mean $=45.6$; standard deviation $=29.07$ ) and doctors and nurses agreeing on choice of care $($ mean $=59.7$; standard deviation $=28.36)$. As many as $46(22 \%)$ of the respondents strongly disagreed with personal inputs of members for planning the care just as $80(39 \%)$ of them disagreed. While $19(9.8 \%)$ strongly disagreed that both doctors and nurses should agree on choice of care with $41(20 \%)$ disagreeing to this.

As shown in Table 6, giving priority to professional status rather than expertise (mean $=62.0$ and $\mathrm{SD}=49.08$ ) was recognized as prominent hindrance to ICP (agreed $120(58.5 \%)$; strongly agreed $-51(24.9 \%))$. Only 10 (4.9\%) respondents strongly disagreed to this, with 23 (11.2\%) disagreeing. Also, hoarding of professional knowledge $($ mean $=59.0 ; \mathrm{SD}=26.35)$ had prominent accep- tance as hindering factor. Fear of loss of professional image and unequal exercise of power between the doctors and nurses in the care process had very close mean (56.5 and 56.3, respectively) and SD (24.47 and 23.13, respectively). Poor knowledge of collaborative practice was considered the least factor $($ mean $=53.7 ; \mathrm{SD}=20$, 95). Sixty-two $(30.2 \%)$ of the respondents agreed to it while $45(22 \%)$ strongly agreed; on the other hand only $25(11.2 \%)$ were strongly against it and 73 $(35.6 \%)$ of the respondents disagreeing that it has impact on ICP.

\section{DISCUSSION}

\subsection{Profession}

There was no association between respondents' profes- 
Table 6. Perceived interdisciplinary collaborative hindrances.

\begin{tabular}{|c|c|c|c|c|c|c|}
\hline Hindrances & Strongly Agree & Agree & Disagree & Strongly Disagree & Mean & Std Dev \\
\hline Unequal power & $\begin{array}{c}55 \\
(26.8 \%)\end{array}$ & $\begin{array}{c}61 \\
(29.8 \%)\end{array}$ & $\begin{array}{c}71 \\
(34.6 \%)\end{array}$ & $\begin{array}{c}18 \\
(8.8 \%)\end{array}$ & 56.3 & 23.13 \\
\hline Hoarding professional knowledge & $\begin{array}{c}59 \\
(28.8 \%)\end{array}$ & $\begin{array}{c}76 \\
(37.1 \%)\end{array}$ & $\begin{array}{c}56 \\
(27.3 \%)\end{array}$ & $\begin{array}{c}14 \\
(6.8 \%)\end{array}$ & 59.0 & 26.35 \\
\hline Higher priority to status than expertise & $\begin{array}{c}51 \\
(24.9 \%)\end{array}$ & $\begin{array}{c}120 \\
(58.5 \%)\end{array}$ & $\begin{array}{c}23 \\
(11.2 \%)\end{array}$ & $\begin{array}{c}10 \\
(4.9 \%)\end{array}$ & 62.0 & 49.08 \\
\hline Fear of potential image loss & $\begin{array}{c}48 \\
(23.4 \%)\end{array}$ & $\begin{array}{c}79 \\
(36.6 \%)\end{array}$ & $\begin{array}{c}59 \\
(28.8 \%)\end{array}$ & $\begin{array}{c}18 \\
(8.8 \%)\end{array}$ & 56.5 & 24.47 \\
\hline Poor knowledge of collaboration & $\begin{array}{c}45 \\
(22.0 \%)\end{array}$ & $\begin{array}{c}62 \\
(30.2 \%)\end{array}$ & $\begin{array}{c}73 \\
(35.6 \%)\end{array}$ & $\begin{array}{c}25 \\
(11.2 \%)\end{array}$ & 53.7 & 20.95 \\
\hline Doctors and nurses not agreeing on patient's needs & $\begin{array}{c}48 \\
(23.4 \%)\end{array}$ & $\begin{array}{c}80 \\
(39.0 \%)\end{array}$ & $\begin{array}{c}58 \\
(28.3 \%)\end{array}$ & $\begin{array}{c}11 \\
(5.4 \%)\end{array}$ & 55.9 & 28.79 \\
\hline
\end{tabular}

sion and their perception of ICP. Doctors were of the opinion that collaborators do not have to agree on choice of patient care particularly at the planning phase while nurses had contrary view. This controversy will most likely lead to unequal exercise of power which is a cog in the wheel of ICP. This finding may be attributed to improper understanding of how collaborative practice operates. Again, the fact that most of the nurses were females (93\%) may have influenced the findings. Females, African females in particular, exhibit less spontaneous decision-making power than their male counterparts and reach out for support of others especially at critical times. This finding is not supportive of collaborative practice which requires power-sharing. The decision on who leads the team should depend on who has the expertise needed at the time as defined by patient's prevailing condition. This is the essence of collaborative practice. As reference [3] observed, combination of skills and knowledge of several health professionals is needed to maximize efficiency of the health care system. No one health profession has all the knowledge needed for total patient care.

\subsection{Gender}

Gender was associated with the respondents' perception of ICP. Female doctors and nurses were more in support of collaborative practice than their male counterparts, thus the findings of [8] support the above views. Although perception of ICP is embedded in the social environment with which the individual interacts, the males seem to prefer independence practice than the females. They would less often consult for decision making. This study, however, did not show at what stage of the care process that collaboration was most unlikely (assessment/ planning/implementation or evaluation stage).

\subsection{Years of Experience}

In line with the assertions of [10], length of experience in clinical practice enhances collaborative practice; the longer the years of experience, the more willing doctors and nurses are likely to collaborate. As experience is said to be the best teacher, those who have spent long time on the job are likely to have appreciated the need to consult with others to minimise mistakes as well as to successfully handle more intricate/complicated cases in their practice through their previous exposures to challenging work situations. Longer period of service, thus, improves the practitioner's use of effective tools in job performance such as team approach to work. Team approach, effective communication and subordination of personal interest to general interest reduce job stress and increase productivity.

\subsection{Enhancers}

Clearly written and oral communication, good working relationships and clarification of individual roles were perceived by the respondents as ICP enhancing factors. Clearly written and oral communication gives sense of direction, prevents confusion and misunderstanding. This agrees with the opinion of [2] that effective communication skill is one of the key elements implicit in collaborative practice. Working together with people that have long practical experience helps to increase knowledge and skill. Good working relationship enhances confidence, understanding and trust which in turn create more room for collaborative practice. This apparently may have led to the positive view of the respondents to this item. Understanding roles to play in a team builds courage and aids display of expertise with significant care delivery efficiency. Role clarification in the presence of good working relationships enhances collaboration, removes confusion and optimizes productivity. With ICP, professional knowledge and skills of different professionals are pooled together to achieve goal-directed client care.

\subsection{Hindrances}

Giving priority to professional status than expertise dur- 
ing intervention was identified as serious hindrance to ICP. Giving priority to status may not give room for use of expertise among those that are considered to have low status but have the skills required for the needed care at a particular time. For example, if status is placed at priority, a junior nurse with better knowledge of life saving skills (LSS) in managing women with obstetric emergencies may be left out in the management decisions. This is waste in health economy and reduces productivity.

Unequal exercise of power tilted more to the side of doctors. Reference [8] observed in their study that physicians were more supportive of collaborative practice led by a physician without power sharing. The doctors are often at the apex position in health institutions and would not like to share power with persons in allied professions. Interdependence and collaboration as a team are still very illusive because of higher priority given to status rather than patient needs pursuit as seen in this study. The strong relationship built under mutual respect, understanding, trust and distributive justice that expectedly should bind doctors and nurses as members of a family with each member being recognized as full-fledged member and contributor to the family's welfare as observed by [2] is severed by this status imposition on collaborative practice.

\section{CONCLUSION}

The study found that doctors and nurses have a positive perception of ICP which was not dependent on one's profession and gender. However, length of experience in clinical practice was seen to enhance collaborative practice; the higher the years of experience, the more willing doctors and nurses are likely to collaborate. While clear communication, role specification and good working relationship were perceived to enhance ICP, status differentiation and decision making power imbalance, knowledge hoarding on the other hand was perceived as hindrances. Measurements to decrease hindrances and improve on the enhancers should be put in place for efficient and effective patient outcomes.

\section{RECOMMENDATION}

There is a need for collaborative continuing education among doctors and nurses to enhance ICP in patient care.

In addition, establishing monthly meetings for doctors and nurses to discuss critical issues and challenges they face in patient/client management in the hospital will go a long way to reduce hindrances to ICP.

The inclusion of interdisciplinary collaborative practice programme into the curriculum of medical and nursing students (where it does not exist) to strengthen collaborative practice when they graduate should be considered. Such provision will decrease hindrances to ICP among these professional groups as well as improve patient outcome.

\section{IMPLICATION FOR NURSING PRACTICE}

The positive perception of doctors and nurses on ICP identified in this study needs to be harnessed for effective, quality and timely client care. Openness, trust relationship and power-sharing implicit in ICP should be plunged into action to enhance actual team working that guarantees positive client outcomes and care provider satisfaction.

\section{LIMITATION OF STUDY}

Dearth of indigenous literature on the topic affected findings of the study. The study was conducted in one teaching hospital which limits generalization since already existing interdisciplinary relationship, hospital policy, practice culture and exposure are capable of affecting the findings. The research dealt with the cognitive and affective domains of the practitioners but not the psychomotor.

\section{ACKNOWLEDGEMENTS}

We thank all the doctors and nurses who willingly agreed to share their experiences in this study. We also express our gratitude to the ethical committee board of the hospital for giving us the opportunity to carry out this research.

\section{REFERENCES}

[1] Carter, K. (2004) An integrated approach. Nursing Times, 91, 212-213.

[2] Berman, A., Synder, S., Kozier, B. and Erb, G. (2008) Fundamentals of nursing: Concept process and practice. 8th Edition, Pearson Prentice Hall, New Jersey.

[3] Mackery, M.A., Sexton, J.B., Freisch, J.A., Holzmueller, C.G., Millman, E.A., Rowen, L. and Provost, P.J. (2008) Operating room teamwork among physicians and nurses: Teamwork in the eye of the beholder. Journal of the American College of Surgeons, 202, 746-52.

[4] Suter, E., Arndt, J., Arthur, N., Parboosingh, J., Taylor, E. and Deutschlander, S. (2009) Role understanding and effective communication as core competencies for collaborative practice. Journal of Interprofessional Care, 23, 4151. doi:10.1080/13561820802338579

[5] Delva, D., Jamieson, M. and Lemieux, M. (2008) Team effectiveness in academic primary health care teams. Journal of Interprofessional Care, 22, 598-611. doi:10.1080/13561820802201819

[6] Kvarnstrom, S. (2008) Difficulties in collaboration: A critical incident study of interprofessional healthcare teamwork. Journal of Interprofessional Care, 22, 91-203. doi:10.1080/13561820701760600 
[7] Miller, K.L., Reeves, S., Zwarenstein, M., Beales, J.D., Kenaszchuk, C. and Conn, L.G. (2008) Nursing emotion work and interprofessional collaboration in general internal medicine wards: A qualitative study. Journal of $\mathrm{Ad}$ vanced Nursing, 64, 332-343. doi:10.1111/j.1365-2648.2008.04768.x

[8] Ben-Arye, W., Charf, M. and Frenkel, M. (2008) How should complementary practitioners and physicians communicate? A cross-sectional from Isreal. Patient Education Counseling, 70, 395-402.

[9] Mohammadreza, H., Hasca, T.J., Cohen, M.J.M., Fields, S.K., Rattner, S.L., Griffith, M., Ibarra, D., De Gonzalez, A.G., Torres-Ruiz, A., Ibarra, G. and Garrcia, A. (2008) Attitude towards nurse physician collaboration: A crosscultural study of male and female nurse/physician collaboration in United States \& Mexico. http://wwwmedscape.com/view

[10] Philips, R.L., Harper, D.C., Kekefield, M., Green, L.A. and Frayer, G.E. (2004) Can nurse practitioner and physicians beat parochialism into plowshares? Health Affairs, 21, 133-142. doi:10.1377/hlthaff.21.5.133
[11] Malcurem, S. (2007) Interprofessional cooperation. Medical education, 29, 65-69.

[12] Seabrook, M. (2003) Overcoming tribalism. Nursing Standard, 14, 261-217.

[13] Lingard, L., Espin, S., Evans, C. and Hawryluck, L. (2004) The rules of the game: Interprofessional collaboration on the intensive care unit team. Critical Care, 8, R403-R408. doi:10.1186/cc2958

[14] Vizirani, S., Hays, R.D., Shapiro, M.F. and Cowan, M. (2008) Effect of a multidisciplinary intervention on communication and collaboration among physicians and nurses. American Journal of Critical Care, 14, 71-77.

[15] Williams, R.G., Silverman, R., Schwind, C., Fortune, J.B., Sutyak, J. and Horvath, K.D. (2007) Surgeon information transfer and communication: Factors affecting quality and efficiency of inpatient care. Annals of Surgery, 245, 159169. doi:10.1097/01.sla.0000242709.28760.56

[16] Uzoagulu, A.E. (1998) Practical guide to writing project reports in tertiary institutions. John Jacobs Classic Publishers, Enugu. 


\section{QUESTIONNAIRE}

Dear Respondent,

This questionnaire is designed to obtain information on the Perception of doctors and Nurses on interdisciplinary collaborative practice in Nnamdi Azikiwe University Teaching Hospital (NAUTH) Nnewi, Nigeria.

This research work is purely for academic purposes and every information supplied will be treated in confidence. Do not write your name.

Thank you for your expected co-operation.

Instructions:

Answer the questions in section A as appropriate. Tick $(\sqrt{ })$ at the column, that represent your opinion against the statement in Section B.

For example, If you "strongly agree", tick "SA"; If you "agree" tick "A"; If you "strongly disagree" tick "SD" and If you "disagree" tick "D".

\section{Section A}

1) Profession

a) Medical doctor $\square$

b) Nurse $\square$

2) Sex

a) male $\square$

b) female $\square$

3) Years of practicing experience

a) 1 - 5 years $\square$

b) 6 yrs and above

\section{Section B}

\begin{tabular}{|c|c|c|c|c|c|}
\hline & Perception on collaborative assessment of patients needs & SA & $\mathbf{A}$ & D & SD \\
\hline 4) & Team approach should be adopted by doctors and nurses in the assessment of patient's needs. & & & & \\
\hline 5) & Doctors and nurses should together have patient's need identification. & & & & \\
\hline 6) & Doctors and nurses do not have to agree on patient's needs before planning for intervention. & & & & \\
\hline
\end{tabular}

\section{Perception on the planning of care collaboratively}

7) The skills of both the doctors and nurses are needed in planning appropriate care for the patient.

8) Doctors and nurses do not have to agree on the care to be selected for the patient's management.

9) Doctors and the nurse have to jointly arrive at a conclusion on who leads the management team considering the condition of the patient and the needed expertise before intervention.

\section{Perception on the implementation of care plan collaboratively}

10) There should be clear communication of actions by both the collaborators.

11) Status should not be considered during the entire process of implementation of care plan.

12) Doctors can influence the nurses' decisions and vice-versa during the intervention phase for goal achievement.

13) Any disagreement on the actions taken by the doctors or nurses does not require joint discussion of the parties to arrive at a common solution.

Factors that enhance collaborative practice

14) Clarification of individual roles in the team.

15) Clearly written and oral communication among the collaborators.

16) Long period of practice experience.

17) Poor working relationship between doctors and nurses does not influence collaborative practice.

\section{Factors that hinder interdisciplinary collaborative practice}

18) Unequal exercise of power between doctors and nurses in the process of collaboration.

19) Giving priority to status than expertise during interventions.

20) Lack of knowledge interdisciplinary collaborative practice.

21) Fear of loss of professional image.

22) Hoarding of professional knowledge. 